NASA Technical Memorandum 106461

AIAA-94-0718

\title{
Rime-, Mixed- and Glaze-Ice Evaluations of Three Scaling Laws
}

David N. Anderson

Lewis Research Center

Cleveland, Ohio

Prepared for the

AIAA 32nd Aerospace Sciences Meeting and Exhibit

sponsored by the American Institute of Aeronautics and Astronautics

Reno, Nevada, January 10-13, 1994

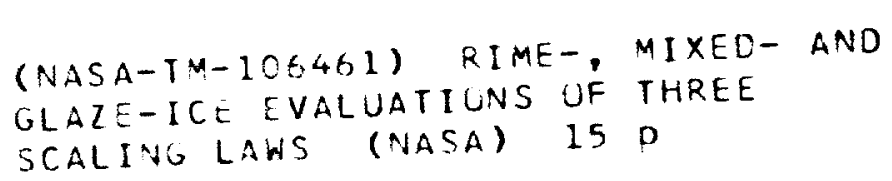

Unclas 


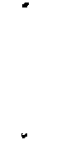




\title{
RIME-, MIXED- AND GLAZE-ICE EVALUATIONS OF THREE SCALING LAWS
}

\author{
David N. Anderson \\ NASA Lewis Research Center \\ Cleveland, Ohio
}

\begin{abstract}
This report presents the results of tests at NASA Lewis to evaluate three icing scaling relationships or "laws" for an unheated model. The laws were $L W C \times$ time $=$ constant, one proposed by a Swedish-Russian group and one used at ONERA in France. Icing tests were performed in the NASA Lewis Icing Research Tunnel (IRT) with cylinders ranging from 2.5 - to $15.2-\mathrm{cm}$ diameter. Reference conditions were chosen to provide rime, mixed and glaze ice. Scaled conditions were tested for several scenarios of size and velocity scaling, and the resulting ice shapes compared. For rime-ice conditions, all three of the scaling laws provided scaled ice shapes which closely matched reference ice shapes. For mixed ice and for glaze ice none of the scaling laws produced consistently good simulation of the reference ice shapes. Explanations for the observed results are proposed, and scaling issues requiring further study are identified.
\end{abstract}

\section{Nomenclature}

$\begin{array}{ll}a & \text { Constant, dimensionless } \\ A_{\mathrm{c}} & \text { Accumulation parameter, dimensionless } \\ b & \text { Relative heat factor, dimensionless } \\ c & \text { Characteristic model length, } \mathrm{cm} \\ c_{p} & \text { Specific heat, cal/g K } \\ h_{c} & \text { Convective film heat-transfer coefficient, } \\ & \text { cal/sec } \mathrm{m}^{2} \mathrm{~K} \\ k & \text { Thermal conductivity, cal } / \mathrm{sec} \mathrm{m} \mathrm{K} \\ L W C & \text { Liquid-water content, } \mathrm{g} / \mathrm{m}^{3} \\ M & \text { Mach number, dimen sionless } \\ n & \text { Freezing fraction, dimensionless } \\ N u & \text { Nusselt number, dimensionless } \\ p & \text { Ambient static pressure, } \mathrm{n} / \mathrm{m}^{2} \\ P_{\mathrm{v}} & \text { Ambient vapor pressure of water, } \mathrm{nt} / \mathrm{m}^{2} \\ R e & \text { Reynolds number, dimensionless } \\ V & \text { Airspeed, } \mathrm{m} / \mathrm{s} \\ t & \text { Ambient static temperature, }{ }^{\circ} \mathrm{C} \\ t_{\text {tot }} & \text { Ambient total temperature, }{ }^{\circ} \mathrm{C} \\ W e & \text { Weber number, dimensionless }\end{array}$

$\begin{array}{ll}\beta_{0} & \begin{array}{l}\text { Droplet catch efficiency at stagnation point, } \\ \text { dimensionless }\end{array} \\ \delta & \text { Droplet median volume diameter, } \mu \mathrm{m} \\ \rho & \text { Density, } \mathrm{g} / \mathrm{cm}^{3} \\ \mu & \text { Viscosity, } \mathrm{g} / \mathrm{cm} \mathrm{s} \\ \sigma_{w / a} & \text { Surface tension of water against air, dyne/cm } \\ \tau & \text { Icing time, min }\end{array}$

\begin{tabular}{ll}
\multicolumn{2}{l}{ Subscripts: } \\
a & Air \\
i & Ice \\
r & Reference size and conditions \\
s & Scale size and conditions \\
w & Water
\end{tabular}

\section{Introduction}

This report presents the initial findings of some recent tests performed at NASA Lewis Research Center to investigate the validity of three icing scaling laws for an unheated model.

In both wind tunnel and flight testing the researcher is often faced with facility or meteorological limitations which prevent testing at desired conditions. For tunnel tests, size restrictions rarely permit the testing of full-size models, and icing facilities can operate over only a limited range of air speeds and water-spray conditions. Flight testing eliminates the need to scale size and airspeed, but because cloud conditions cannot be controlled test-condition scaling is generally required. There is therefore a crucial need for reliable techniques to permit the scaling of size and test conditions in such a way that ice shapes resulting from scaled tests adequately simulate reference (full-size) results.

A number of scaling laws have been derived by researchers over the past 30 years or so (see refs. 1-6.) Each of these laws consists of a set of relatively simple equations which relate scale test conditions to the reference conditions when scale size and at least one other 
scale variable (usually airspeed) have been defined.

For this study, only three of the several published scaling laws were considered. They were: $L W C \times$ time $=$ constant, the Swedish-Russian law ${ }^{4}$, and the French law ${ }^{5}$. Tests were performed in the Lewis Icing Research Tunnel (IRT) with cylinders as the test models. To evaluate $L W C \times$ time = constant, several tests were conducted with different liquid-water contents and spray times but with cylinder size and all other test conditions the same from test to test. Liquid-water contents ranged from .4 to $.7 \mathrm{~g} / \mathrm{m}^{3}$ for one series of tests and from .8 to $1.3 \mathrm{~g} / \mathrm{m}^{3}$ for others. For the Swedish-Russian and French laws, the cylinder size and tunnel and cloud conditions were selected to define reference conditions and the scaled cylinder size and airspeed chosen. Each law was then applied to determine the remaining scaled test conditions. Reference conditions included cylinder diameters of 15.2 and $5.1 \mathrm{~cm} \mathrm{(6} \mathrm{and} 2$ in), total temperatures of -26 to $-8^{\circ} \mathrm{C}$ $\left(-15\right.$ to $\left.18^{\circ} \mathrm{F}\right)$, velocities of 76 to $94 \mathrm{~m} / \mathrm{s}$ (170 to $210 \mathrm{mph}$ ), median volume droplet diameters of 28 to $30 \mu \mathrm{m}$, liquidwater contents of .6 to $1.3 \mathrm{~g} / \mathrm{m}^{3}$, and spray times of 7.8 to $18.3 \mathrm{~min}$. These test conditions resulted in rime, mixed and glaze ice. Scaling scenarios tested included scale-toreference size ratios of $1: 1$ and $1: 2$ and scale-to-reference velocity ratios ranging from $1: 1$ to $1: 2$. The criteria for successful scaling were that the scaled ice shape should simulate the reference shape and that the amount of ice accreted in the scaled test, corrected for the model size, should match the reference quantity.

In this report, the scaling laws will be described and experimental ice shapes for reference and scaled conditions compared. Explanations for the observed results will be proposed, and scaling issues requiring further study will be identified.

\section{Considerations in the Development of Scaling Laws}

In an attempt to analyze the icing scaling problem rigorously, Bilanin ${ }^{7}$ identified 18 dimensionless groups which affect the normalized ice thickness. A consideration of three of these similarity parameters, the Mach number, the Reynolds number and the Weber number, illustrates the fundamental difficulty of icing scaling anal- ysis:

$$
\text { and } \begin{aligned}
M & =\frac{V^{2}}{c_{\mathrm{p}, T_{\mathrm{a}}}} \\
\operatorname{Re} & =\frac{V c \rho_{\mathrm{a}}}{\mu_{\mathrm{a}}} \\
W e & =\frac{V^{2} c \rho_{\mathrm{a}}}{\sigma_{\mathrm{w} / \mathrm{a}}}
\end{aligned}
$$

Because the temperatures of interest to icing extend over a very narrow range on the absolute temperature scale, $T_{\mathrm{a}}, c_{\mathrm{p}, \mathrm{e}^{\prime}} \mu_{\mathrm{a}}$ and $\sigma_{\mathrm{w} / \mathrm{a}}$ are effectively constant. Thus, to match the Mach number between scale and reference cases requires

$$
V_{s}=V_{r}
$$

The altitudes at which icing occurs are generally low enough that test facility total pressures are close to flight icing-encounter total pressures. In this case, scale and reference $\rho$ are nearly equal. Then to match the Reynolds number requires

$$
V_{\mathrm{s}}=\frac{{ }^{c} \mathrm{r}}{c_{\mathrm{s}}} V_{\mathrm{r}}
$$

and to match the Weber number requires

$$
V_{\mathrm{s}}=\frac{c_{\mathrm{r}}^{.5}}{c_{\mathrm{s}}{ }^{5}} V_{\mathrm{r}}
$$

Clearly, it is impossible to satisfy similarity of Mach, Reynolds and Weber numbers simultaneously, except for the special case in which both scale size and velocity equal their respective reference values. The Mach number can be neglected because at the relatively low speeds of interest to icing, compressibility effects are small. Even with this simplification, however, equations (5) and (6) are inconsistent, and each requires scale velocities greater than the reference when the scale size is less than the reference. Because test velocities greater than typical flight airspeeds are not generally achievable in icing test facilities, equations (5) and (6) impose imprac- 
tical restrictions.

This dilemma is overcome in the existing analyses by arguing that not only are compressibility effects negligible, but viscous effects are as well, so that the scale and reference Reynolds numbers need not be matched. The rationale for this additional simplification has been that icing primarily occurs at the leading edge where the boundary layer is still thin ${ }^{6}$. In addition, conventional scaling analyses make no attempt to match the Weber number; thus, they have assumed that water surface tension has no influence on ice growth. Instead of attempting to satisfy equations (1) - (3), existing scaling methods assume that the scale and reference cases will have similarity of geometry and of both pressure and velocity flowfields around the model. The scaling equations are then derived by applying the continuity (water-catch analysis), momentum (droplet-trajectory analysis) and energy (surface heat-balance analysis) equations to the ice-accretion process at the model stagnation line. The basic derivations on which most of the various laws are based has been given by Ruff .

\section{Scaling Laws Tested}

The sets of equations used for each of the three laws considered in this study will be given here. These equations have been incorporated into a NASA Lewis computer code to permit ready determination of scale conditions for different test cases.

\section{Constant Product of Liquid-Water Content and Time} This law considers the special case for which only scale liquid-water content and time are permitted to differ from the reference values. It is is the most restrictive of the three laws tested and is based on the least analysis. The analysis includes only water-catch considerations to insure that scale and reference ice accumulations are matched. However, this law also matches the droplet trajectory by requiring that the scale model size, airspeed, pressure and water droplet size be the same as the reference values. The scale and reference temperature are required to have the same value, but this is not sufficient to insure that the surface heat balances will match. Because of the restrictions in test conditions, this law also coinci- dentally satisfies similarity of Mach number, Reynolds number and Weber number; it is the only scaling law considered here to do so.

The water-catch analysis identifies a term called the accumulation parameter; it is defined as

$$
A_{\mathrm{c}}=\frac{L W C V \tau}{c \rho_{\mathrm{i}}}
$$

The scale and reference accumulation parameters must be matched along with the catch efficiencies, $\beta_{0}$, to insure equal normalized ice thicknesses. For this law, the scale and reference values of model size, $c$, airspeed, $V$, and median volume droplet diameter, $\delta$, are matched; thus, the catch efficiency, which is a function of all three parameters, is also matched. Therefore, equation (7) shows that in order for the scale and reference normalized ice thicknesses to be the same, the product of liquidwater content and time must be the same. The complete set of equations to be satisfied is then

$$
\begin{gathered}
c_{\mathrm{s}}=c_{\mathrm{r}} \\
V_{\mathrm{s}}=V_{\mathrm{r}} \\
p_{\mathrm{s}}=p_{\mathrm{r}} \\
\delta_{\mathrm{s}}=\delta_{\mathrm{r}} \\
(L W C)_{\mathrm{s}}=[\text { selected by user }] \\
\tau_{s}=\tau_{\mathrm{r}} \frac{L W C_{\mathrm{r}}}{L W C_{s}} \\
t_{\mathrm{s}}=t_{\mathrm{r}}
\end{gathered}
$$

If the reference conditions, $c_{\mathrm{r}}, V_{\mathrm{r}^{\prime}}, p_{\mathrm{r}}, \delta_{\mathrm{r}},(L W C)_{\mathrm{r}^{\prime}} t_{\mathrm{r}}$ and $\tau_{\mathrm{r}}$ are known and a value for the scale liquid-water content, $(L W C)_{\mathrm{s}}$, is chosen, then all the scale parameters can be determined from eqs. (8-14).

2. Swedish-Russian This law was developed by a joint Swedish-Soviet working group on flight safety ${ }^{4}$. In addition to the water-catch considerations of the previous 
law, it includes a droplet-trajectory analysis. Energybalance similarity is approximately satisfied by setting the scale temperature and liquid-water content equal to their respective reference values. The user selects the scale size and airspeed. The static pressure in most facilities, including the IRT, cannot be controlled, so it is determined by airspeed and ambient pressure. The complete scale conditions are then given in the following equations:

$$
\begin{gathered}
c_{\mathrm{s}}=[\text { selected by user }] \\
V_{\mathrm{s}}=[\text { selected by user }] \\
p_{\mathrm{s}}=[\text { fixed by conditions] } \\
\delta_{\mathrm{s}}=\delta_{\mathrm{r}}\left(\frac{c_{\mathrm{s}}}{c_{\mathrm{r}}}\right)^{-5}\left(\frac{V_{\mathrm{s}}}{V_{\mathrm{r}}}\right)^{-5} \\
(L W C)_{\mathrm{s}}=(L W C)_{\mathrm{r}} \\
\tau_{\mathrm{s}}=\tau_{\mathrm{r}}\left(\frac{c_{\mathrm{s}}}{c_{\mathrm{r}}}\right)\left(\frac{V_{\mathrm{s}}}{V_{\mathrm{r}}}\right)^{-1} \\
t_{\mathrm{s}}=t_{\mathrm{r}}
\end{gathered}
$$

3. French The French scaling law was developed by researchers at ONERA ${ }^{5}$. This law includes an analysis for surface energy balance in addition to the analyses for water catch and droplet trajectory. The energy-balance analysis is based on the work of Messinger ${ }^{8}$. Unlike the other laws considered here, no scale parameters are required to equal their reference values. As used in this study, the French scaling law is:

$$
\begin{gathered}
c_{\mathrm{s}}=[\text { selected by user }] \\
V_{\mathrm{s}}=[\text { selected by user }] \\
p_{\mathrm{s}}=[\text { fixed by conditions }] \\
\delta_{\mathrm{s}}=\delta_{\mathrm{r}}\left(\frac{c_{\mathrm{s}}}{c_{\mathrm{r}}}\right)^{.62}\left(\frac{p_{\mathrm{s}}}{p_{\mathrm{r}}}\right)^{.24}\left(\frac{V_{\mathrm{s}}}{V_{\mathrm{r}}}\right)^{-.38}
\end{gathered}
$$

$$
\begin{array}{r}
t_{\mathrm{s}}=t_{\mathrm{r}}+\frac{1.058 \times 10^{6} \mathrm{Knt} / \mathrm{m}^{2}}{1+b}\left(\frac{1}{p_{\mathrm{s}}}-\frac{1}{p_{\mathrm{r}}}\right)- \\
\frac{1732 \mathrm{~K}}{1+b}\left\{\left(\frac{p_{\mathrm{v}}}{p}\right)_{\mathrm{s}}-\left(\frac{p_{\mathrm{v}}}{p}\right)\right\}- \\
\frac{(3.646+b)\left(V_{\mathrm{s}}^{2}-V_{\mathrm{r}}^{2}\right)}{(1+b) 8373 \mathrm{~m}^{2} / \mathrm{s}^{2} \mathrm{~K}}
\end{array}
$$

Because the ambient vapor pressure of water, $p_{v}$, is a function of temperature, equation (28) must be solved iteratively to find the air temperature of the scale case.

The development of equation (28) from the Messinger analysis ${ }^{8}$ requires that the scale values of freezing fraction, $n$, and relative heat factor, $b$, be equal to their respective reference values. The freezing fraction is the fraction of water arriving at a given location on the model which freezes at that location. The relative heat factor was defined by Tribus ${ }^{9}$ as

$$
b=\frac{L W C_{\mathrm{r}} V_{\mathrm{r}} \beta_{0} c_{\mathrm{p}, \mathrm{w}}}{h_{\mathrm{c}}}
$$

Here, $c_{p, w}$ is the specific heat of water at the surface temperature of the model, and $h_{\mathrm{c}}$ is the surface convective heat transfer coefficient. $h_{\mathrm{c}}$ can be found from the Nusselt number, $N u$, using the usual definition,

$$
h_{\mathrm{c}}=N u k_{\mathrm{a}} / c
$$

Equation (26) results from equating the scale and reference relative heat factors. It can be seen from the exponents in this equation that the Nussselt number and Reynolds number, $R e$, are assumed to be related as

$$
N u=a R e^{.8}
$$


In the studies reported here, a value of .033 was used for the constant $a$. In equation (31) the Reynolds number is based on the airspeed, $V$, and the characteristic dimension of the model, $c$ :

$$
\operatorname{Re}=V c \rho_{\mathrm{a}} / \mu_{\mathrm{a}}
$$

The scale static temperature found from equation (28) is insensitive to the value of $b$ from equation (29). Thus, although the droplet catch efficiency, $\beta_{0}$, that appears in equation (29) can be determined by the method given by Langmuir and Blodgett ${ }^{10}$, for this study it was sufficiently accurate to use a value of $\beta_{0}=.5$.

The derivation of equation (28) assumes that the surface is at the freezing temperature of water. This assumption is only valid if the freezing fraction, $n$, is less than one. Because of this assumption about the surface temperature, equation (28) is not strictly applicable to rime-ice conditions. However, for rime conditions water freezes immediately on impact, and the ice shape is insensitive to the ambient temperature. Thus, the temperature found from equation (28) is adequate for scaling as long as the scaled ice is also rime. In this study, equation (28) was used for rime as well as for mixed and glaze ice.

\section{Description of Experiment}

NASA Lewis Icing Research Tunnel The experiments were performed in the NASA Lewis Icing Research Tunnel (IRT) shown in figure $1^{11}$. The IRT has a test

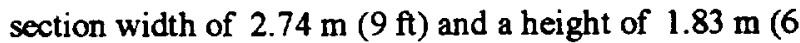
ft.) With an empty test section, it is capable of operation at test-section velocities up to $130 \mathrm{~m} / \mathrm{s}(300 \mathrm{mph})$. A refrigeration system permits accurate control of the testsection temperature from -40 to $0^{\circ} \mathrm{C}\left(-40\right.$ to $\left.32^{\circ} \mathrm{F}\right)$. A water-spray system ${ }^{12}$ with 8 spray bars containing approximately 100 spray nozzles provides the ability to control test-section liquid-water content from .2 to $3 \mathrm{~g} / \mathrm{m}^{3}$ and droplet median volume diameters from 15 to $40 \mu \mathrm{m}$.

Two sets of spray nozzles, known as the mod-1 and standard nozzles, are used in the IRT to provide different ranges of liquid-water content and droplet size $e^{12}$. Both nozzles were used in these tests. Some spray conditions can be obtained with either nozzle set, and studies have shown that the ice shape for a given set of conditions is independent of the nozzle type ${ }^{13}$.

Scaling Test Hardware. Ice accretion was measured on hollow circular aluminum cylinders with 15.2-, 7.6-, 5.1and 2.5-cm (6-, 3-, 2- and 1-in) diameters. Each cylinder was mounted vertically in the center of the test section as shown in figure 2. As seen in figure 2(a), the 15.2-, 7.6and 5.1-cm (6-, 3- and 2-in) cylinders were installed with a short mounting cuff at each end. The cuffs were attached to aluminum angles mounted on the ceiling and floor of the tunnel test section. These cylinders extended over the full height of the test section. The $2.5-\mathrm{cm}$ ( 1 -in) cylinder was installed as shown in Figure 2(b). It hung from a sleeve mounted to a plate attached to the test-section ceiling, and it extended just below the center of the tunnel. All cylinders were marked with a line around their circumference to identify the middle of the test section. All ice tracings were made at this location.

Test_Procedure. Tests were performed by first establishing the tunnel velocity and total temperature. The pressures of the spray-bar water and atomizing air, which determine $L W C$ and $\delta$, were then set, and when tunnel conditions had stabilized, the water spray was initiated. To account for the start-up transient, spray times for the tests were increased by $12 \mathrm{~s}$ from the values determined from the scaling laws. This addition was never more than 4 percent of the total spray time, and it will not be included in the times reported here. When the prescribed spray period was completed, the spray was shut off and the tunnel brought to idle to permit personnel entry into the test section. After the ice shape had been recorded, the ice was cleaned from the model and the procedure repeated for the next spray condition.

The ice shape was recorded manually for each test. A heated aluminum block with a semicircular cut-out matching the cylinder was used to melt a thin cut into the ice normal to the cylinder axis at the center of the test section. A cardboard template, also with a semicircular cutout to match the cylinder, was placed in this gap, and the ice shape was traced onto the cardboard template. The tracing was later digitized for computer storage. 


\section{Results}

Test Repeatability Evaluations in this study were based on judging differences in ice shape from one run to another. Thus it was also necessary to establish, for a benchmark, the typical variation in ice shapes from run to run when identical tunnel conditions were specified. Ice accretes on tunnel components during the course of each day's testing, possibly altering the tunnel flow and spray characteristics. It might also be possible for the tunnel or spray bar characteristics to change for a variety of reasons over longer periods of time. To address these possibilities, extensive repeatability tests have been performed in the IRT by Shin and Bond ${ }^{13}$. Their tests showed that repeatability of ice shapes on airfoils was generally excellent. In view of these results, it was not necessary to perform additional comprehensive repeability testing; however, to achieve the purposes of the present study, several sets of test conditions were repeated from time to time.

Figure 3 presents typical data for repeatability tests performed on the 15.2-cm- (6-in-) diameter cylinder (fig. 3(a)) and the 5.1-cm (2-in) cylinder (fig. 3(b).) The 15.2-cm (6-in) cylinder tests reported in figure 3 (a) show that the amount of ice accreted and the lower horn size were consistent from run to run. The upper horn size and location varied somewhat, however.

Figure 3(b) shows results for the same operating conditions as $3(\mathrm{a})$ but for a $5.1-\mathrm{cm}$ - (2-in-) diameter cylinder. Only two tests were made for this cylinder at these conditions, and very little variation in the ice shapes was observed. Additional repeatability tests were also made for other cylinders at various conditions; the results shown here are representative of the ice-shape variation observed.

Scaling With Constant $L W C x T$ Time Figure 4 gives three sets of results for the $L W C \times$ time $=$ constant law. All tests were made with a tunnel airspeed of $94 \mathrm{~m} / \mathrm{s}$ (210 mph).

Figure 4(a) compares results on a 15.2-cm (6-in) cylinder at a total temperature of $-26^{\circ} \mathrm{C}\left(-14^{\circ} \mathrm{F}\right)$ and a droplet median volume diameter of $30 \mu \mathrm{m}$. Three liquid-water contents were tested, $.8,1.0$ and $1.3 \mathrm{~g} / \mathrm{m}^{3}$, and the respective spray times were $12.7,10.1$ and $7.8 \mathrm{~min}$. For these rime-ice conditions, both the quantity of ice accreted and the ice shape were preserved for all three tests, showing that this scaling law applies for these conditions.

Ice shapes on the $5.1-\mathrm{cm}$ - (2-in-) diameter cylinder for a somewhat higher temperature and lower liquid-water contents are shown in figure 4(b). At the lowest liquidwater content shown, $.4 \mathrm{~g} / \mathrm{m}^{3}$, the ice shape suggested that little water runback occurred. When the liquid-water content was increased to $.5 \mathrm{~g} / \mathrm{m}^{3}$, the higher water loading reduced the freezing fraction, and water runback from the stagnation region increased. As a result, a small valley formed in the ice at the stagnation line with stubby horns adjacent to it. Finally, a liquid-water content of $.7 \mathrm{~g} / \mathrm{m}^{3}$ produced a still deeper valley and even more pronounced horns. Although total ice accumulation appeared to be constant for these three tests, the ice shape was not.

Figure 4(c) shows ice shapes on the $5.1-\mathrm{cm}$ (2-in) cylinder at the same temperature as figure 4(b) but with a different drop size and with liquid-water contents of $.8,1$ and $1.3 \mathrm{~g} / \mathrm{m}^{3}$. These conditions resulted in fully glaze ice shapes. The ice thickness near the stagnation line was similar for all three tests, and the total ice accumulation appeared to be the same. However, the angle between the horns increased significantly when liquid-water content increased from .8 to $1 \mathrm{~g} / \mathrm{m}^{3}$ and from 1 to $1.3 \mathrm{~g} / \mathrm{m}^{3}$. As with the mixed-ice conditions of figure $4(\mathrm{~b})$, these results illustrate how liquid-water content can have a significant effect on ice shape.

$L W C \times$ time $=$ constant satisfies Mach-, Reynolds- and Weber-number similarity, and both water catch and droplet trajectory are matched. Although it's not clear if all these features are required, application of this law produced a constant amount of ice for a range of liquidwater contents for rime, mixed and glaze ice. However, except for fully rime conditions, ice shapes could not be scaled with this law. The reason is that the liquid-water content can have a significant effect on the surface heat balance, and this law does not match surface heat balance terms between scale and reference conditions. These results show that it is not sufficient to scale icing 
encounters by satisfying similarity in Mach number, Reynolds number, Weber number, droplet trajectory and water catch alone. It is also necessary that the surface heat balance for the scale test be matched to the reference.

Scaling Using Swedish-Russian and Erench Laws These two laws do not satisfy similarity in Mach number, Reynolds number and Weber number, but each includes some consideration of the leading-edge heat balance. Results of tests to evaluate the Swedish-Russian and French laws are shown in figures 5,6 and 7 . In each figure, the ice shape for the scaled tests are compared to the reference shape.

Figure 5 gives rime-ice results. In figure 5 (a) the model size was scaled from 15.2 to $7.6 \mathrm{~cm}$ ( 6 to $3 \mathrm{in}$ ) and the airspeed was scaled from 76 to $61 \mathrm{~m} / \mathrm{s}$ (170 to $136 \mathrm{mph}$ ). The quantity of ice accreted and the shape of the scaled ice agreed very closely with the reference ice for both laws.

Scaling the size from 5.1 to $2.5 \mathrm{~cm}$ ( 2 to 1 in) and the airspeed from 94 to $47 \mathrm{~m} / \mathrm{s}$ ( 210 to $105 \mathrm{mph}$ ) produced the rime ice shapes shown in figure 5 (b). For this situation, the scaled ice shapes were a reasonable, although not perfect, match of the reference shape. It appears that the reference conditions resulted in slightly less freezing occurring along the stagnation line than occurred for either of the scaled conditions. However, it can be concluded that for rime conditions, both of these scaling laws provided adequate scaling guidance.

Figure 6 gives results at mixed-ice conditions. For both figures $6(\mathrm{a})$ and $6(\mathrm{~b})$, the size was scaled from 5.1 to 2.5 $\mathrm{cm}$ ( 2 to $\mathrm{I}$ in). In figure $6(\mathrm{a})$, the scale and reference airspeeds were matched at $94 \mathrm{~m} / \mathrm{s}(210 \mathrm{mph})$ while for figure $6(\mathrm{~b})$ airspeed was scaled from 76 to $61 \mathrm{~m} / \mathrm{s}$ (170 to $136 \mathrm{mph}$ ). For the scaling situations of both figures, the quantity of ice accreted seemed to match the reference quantity fairly well when the French law was used, while the Swedish-Russian law may have produced somewhat too much ice.

For the cases presented in figures $6(\mathrm{a})$ and $6(\mathrm{~b})$, the scaled ice shapes for both laws only approximately simu- lated the reference shapes. The reference shapes had deeper troughs and more pronounced horns than either of the scaled shapes, suggesting that the reference case had a lower freezing fraction at the leading edge. The Swedish-Russian law makes no attempt to match scale and reference freezing fraction; it satisfies the heat balance by simply matching scale and reference static temperature and liquid-water content. As noted earlier, the French law does match the freezing fraction. However, it's not sufficient just to match the freezing fraction; the physical model on which it is based must also be correct.

The freezing fraction depends in part on the value of the heat-transfer film coefficient. As noted earlier, the French law assumes the Nusselt number to be proportional to the Reynolds number raised to the 8 power. Experimental airfoil data of Gelder and Lewis ${ }^{14}$ showed that for turbulent boundary-layer flow, $N u \propto R e^{.8}$, while for laminar boundary-layer flow (near the leading edge), $N u \propto R e^{.5}$. Gelder and Lewis based their Reynolds numbers on the local velocity and their Nusselt and Reynolds numbers on the distance along the surface from the leading edge. Van Fossen, et. al. ${ }^{15}$ measured heat transfer on cylinders with and without artificial ice shapes for Reynolds numbers up to about $1.9 \times 10^{5}$. These Reynolds numbers were based on the cylinder diameter and freestream velocity. At the leading edge the Nusselt number, also using cylinder diameter, varied with the Reynolds number raised to a power near .5 for low turbulence and unroughened model surfaces. In the tests reported here, the Reynolds number based on cylinder diameter and free-stream velocity (eq. (2)) varied from approximately $10^{5}$ to $10^{6}$. Thus, for these conditions, the .5 power may be more appropriate than the .8 power used by the French scaling law. In its present form, the French scaling law may be more suitable for high-Reynolds-number applications. It should be noted that the AEDC-law ${ }^{6}$ analysis was based on a power of .5; thus, it may be a better choice for scaling at low Reynolds numbers.

The effect of changing the Reynolds-number power from .8 to .5 in the French analysis can be seen by equating the scale and reference relative heat factors using $N u \propto R e^{.5}$. Equation (26) then becomes 


$$
(L W C)_{s}=(L W C)_{r}\left(\frac{p_{3}}{p_{r}}\right)^{.5}\left(\frac{c_{8}}{c_{r}}\right)^{-5}\left(\frac{V_{8}}{V_{8}}\right)^{-.5}
$$

If equation (33) had been used instead of equation (26), $L W C_{\text {f }}$ for the case of figure 6(a) would have been $.85 \mathrm{in}$ stead of $7 \mathrm{~g} / \mathrm{m}^{3}$. For figure $6(\mathrm{~b}), L W C_{\text {, would have been }}$ 1.25 instead of $.95 \mathrm{~g} / \mathrm{m}^{3}$. Higher liquid-water contents decrease the freezing fraction, and the lower freezing fractions would tend to reduce the leading-edge ice thickness and increase the horn size. This effect was illustrated in figure 4(b) which showed ice shapes for mixedice conditions with three liquid-water contents. Thus, the change in Reynolds-number power from .8 to .5 is in the right direction to improve the agreement between the scaled and reference ice shapes, but additional test data are needed to confirm the validity of this change. HighReynolds-number data to verify the existing French law and low-Reynolds-number data for the AEDC law are needed as well.

Typical glaze-ice test results are presented in figure 7. Reference conditions for the tests of both figure 7(a) and (b) were identical except for the reference model size. Figure 7(a) presents results for scaling velocity from 94 to $58 \mathrm{~m} / \mathrm{s}$ ( 210 to $130 \mathrm{mph}$ ) with the cylinder diameter of 15.2-cm (6-in) matched. For this situation, application of the scaling laws produced somewhat more ice than the reference test while the scale horns were less distinct than the reference. The reference conditions for figure 7(a) were the subject of the repeatability study reported in figure 3(a). It is evident that the differences between the scaled and reference ice accretions in figure $7(a)$ are greater than the typical run-to-run variations shown in figure 3(a).

Glaze results for the 5.1-cm (2-in) cylinder are shown in figure $7(\mathrm{~b})$. Both size and velocity were scaled in this case. Again, both scaling laws led to a significantly larger ice accretion than the reference conditions, and the prominent horns of the reference ice shape have been totally lost. The comments about the poorly-scaled shapes of figures 6(a) and (b) also apply here and need not be repeated. Possible reasons for the poor simulation of the total amount of ice accreted will be discussed further.
Both the Swedish-Russian and French laws match the accumulation parameter, $A_{\mathrm{c}}$, and the droplet catch efficiency, $\beta_{0}$, between scale and reference conditions. The close match of reference and scaled ice accretions for rime and mixed conditions verify that these effects have been properly addressed. Therefore, the excess quantity of scaled ice accreted for the glaze cases must have resulted from neglected phenomena which are of importance only for glaze ice.

One such phenomenon is droplet splashing. If droplet splashing has a significant effect on ice accretion for glaze ice, the Weber number would need to be matched between scale and reference tests ${ }^{7}$. For the present tests the Weber number for the scale tests was lower than the reference, and the tendency for splashing in the scale tests was therefore less than in the reference.

Another mechanism potentially leading to reduced ice accretion is shedding of liquid water from the surface ${ }^{16,17}$. The scaled Reynolds numbers for both figures 7 (a) and (b) were smaller than their respective reference values. Consequently, the surface water in the scaled tests would have experienced lower shear than if $R e$ had been matched.

The ability of the $L W C \times$ time = constant law, which satisfies similarity in both Weber and Reynolds numbers, to maintain constant quantities of ice provides additional evidence that these parameters may be too important to neglect for glaze-ice conditons. Studies of the effects of both the Weber and Reynolds numbers are needed to improve our understanding of the physics of ice accretion. A better physical understanding is essential not only for the development of more effective scaling methodologies but also for the evolution of more accurate ice-accretion codes.

\section{Concluding Remarks}

Three scaling laws, $L W C \times$ time $=$ constant, the SwedishRussian law and the French law, were used to scale from reference conditions representing rime, glaze and mixed-ice conditions for an unheated model. Tests of the Swedish-Russian and French laws included scaling of 
size alone, velocity alone, and of both size and velocity.

The three laws represent a progression in analytical thoroughness with the $L W C \times$ time = constant law involving the simplest analysis. This law satisfies similarity of Mach number, Reynolds number and Weber number. It always provided accurate simulation of the amount of ice accreted. However, it includes no consideration of heat balance; consequently, for mixed or glaze-ice conditions it did not scale ice shapes adequately for the liquid-water contents tested (.4 to $1.3 \mathrm{~g} / \mathrm{m}^{3}$ ). This law can be expected to be valid in general only for rime conditions, for which water freezes instantly on impact; i.e., for situations for which the surface heat balance has no effect on the ice shape.

The Swedish-Russian and French laws gave nearly the same results. For rime ice, both laws produced scaled ice shapes that closely matched the reference. For mixed and glaze ice, the scaled ice shapes were only approximate simulations of the reference shapes, having lesspronounced horns. Because the form of the Nusselt number, $N u \propto R e^{.8}$, used in the French-law analysis is applicable to higher Reynolds numbers than were tested in this study, it was speculated that better results might be achieved with a modified form of this law using a Reynolds-number power of .5 instead. Additional tests at the Reynolds numbers tested here, $10^{5}$ to $10^{6}$, are needed to evaluate the effect of the Reynolds-number power on scaling results, and tests at higher Reynolds numbers are neoded to test the validity of the French scaling law in its present form.

For glaze conditions not only was the shape incorrectly scaled, but the quantity of scaled ice accreted was too great when either the Swedish-Russian or French laws was used. Neither of these laws satisfies similarity of Reynolds or Weber number. Because the $L W C \times$ time $=$ constant law satisfies similarity of Reynolds and Webernumber and also produced the correct amount of glaze ice, it was reasoned that features of the ice-accretion process which depend on the Reynolds and Weber numbers may need to be included in analyses to adequately scale for glaze-ice conditions. In particular, phenomena such as droplet splashing and liquid-water shedding were considered by Bilanin ${ }^{7,16}$ and Olsen ${ }^{17}$ to be relevant to ice accretion. Tests are needed to establish their importance. It is not clear how a practical scaling methodology which includes Reynolds and Weber number matching could be developed; however, studies to increase our understanding of the ice-accretion process should lead not only to improved scaling methodologies but also to more accurate ice-accretion codes. For many situations it may not be possible to derive exact scaling procedures, but approximations based on a good physical understanding and supported by accurate analytical tools should prove to be adequate to satisfy the needs of icing experiments.

\section{References}

1. Sibley, E.J. and Smith, R.E.: Model Testing in an Icing Wind Tunnel, Lockheed Aircraft Corporation, California Division, Report LR10981, Oct. 1955.

2. Dodson, E.D.: Scale Model Analogy for Icing Tunnel Testing, Boeing Airplane Company, Transport Division Document no. D6-7976, 1962.

3. Hauger, H. and Englar, K.: Model Testing in an Icing Wind Tunnel -- Theory and Limitaions, Douglas Aircraft Report S.M. 14993, 1954.

4. Ingelman-Sundberg, M., Trunov, O.K. and Ivaniko, A.: Methods for Prediction of the Influence of Ice on Aircraft Flying Characteristics, Swedish-Soviet Working Group on Flight Safety, 6th Meeting, Report No. JR-1, 1977.

5. Charpin, Francois and Fasso, Guy: Icing Testing in the Large Modane Wind Tunnel on Full Scale and Reduced Scale Models, L'Aeronautique et l'Astronoutique, no 38, 1972 . English translation published as NASA TM-75373.

6. Ruff, G.A.: Analysis and Verification of the Icing Scaling Equations, AEDC-TR-85-30, Vol 1 (Rev), March 1986.

7. Bilanin, A. J.: Proposed Modifications to the Ice Accretion/Icing Scaling Theory, AIAA Paper AIAA88-0203, January 1988.

8. Messinger, B.L.: Equilibrium Temperature of an Unheated Icing Surface as a Function of Airspeed, $J$. Aeron. Sci., 20 No. 1, Jan. 1953, pp 29-42. 
9. Tribus, Myron; Young, G.B.W.; and Boelter, L.M.K.: Analysis of Heat Transfer Over a Small Cylinder in lcing Conditions on Mount Washington, Trans ASME, vol. 70, pp971-976, 1948.

10. Langmuir, Irving and Blodgett, Katharine B.: A Mathematical Investigation of Water Droplet Trajectories, Army Air Forces Technical Report No. 5418, February 1946.

11. Sceder, Ronald H. and Andracchio, Charles, R.: NASA Lewis Icing Research Tunnel User Manual, NASA TM 102319, June 1990.

12. Ide, Robert F.: Liquid Water Content and Droplet Size Calibration of the NASA Lewis Icing Research Tunnel, NASA TM 102447, Jan 1990.

13. Shin, Jaiwon and Bond, Thomas H.: Results of an Icing Test on a NACA 0012 Airfoil in the NASA
Lewis Icing Research Tunnel, NASA TM-105374, ALAA-92-0647, Jan. 1992.

14. Gelder, Thomas F. and Lewis, James P.: Comparison of Heat Transfer from Airfoil in Natural and Simulated Icing Conditions, NACA TN-2480, September, 1951.

15. Van Fossen, G.J., Simoneau, R.J., Olsen, W.A., Jr. and Shaw, R.J.: Heat Transfer Distributions Around Nominal Ice Accretion Shapes Formed on a Cylinder in the NASA Lewis Icing Research Tunnel, AIAA-84-0017 and NASA TM-83557, January, 1984.

16. Bilanin, Alan J.: personal communication.

17. Olsen, W. and Walker, E.: Experimental Evidence for Modifying the Current Physical Model for Ice Accretion on Aircraft Surfaces, NASA TM-87184, May, 1986. 


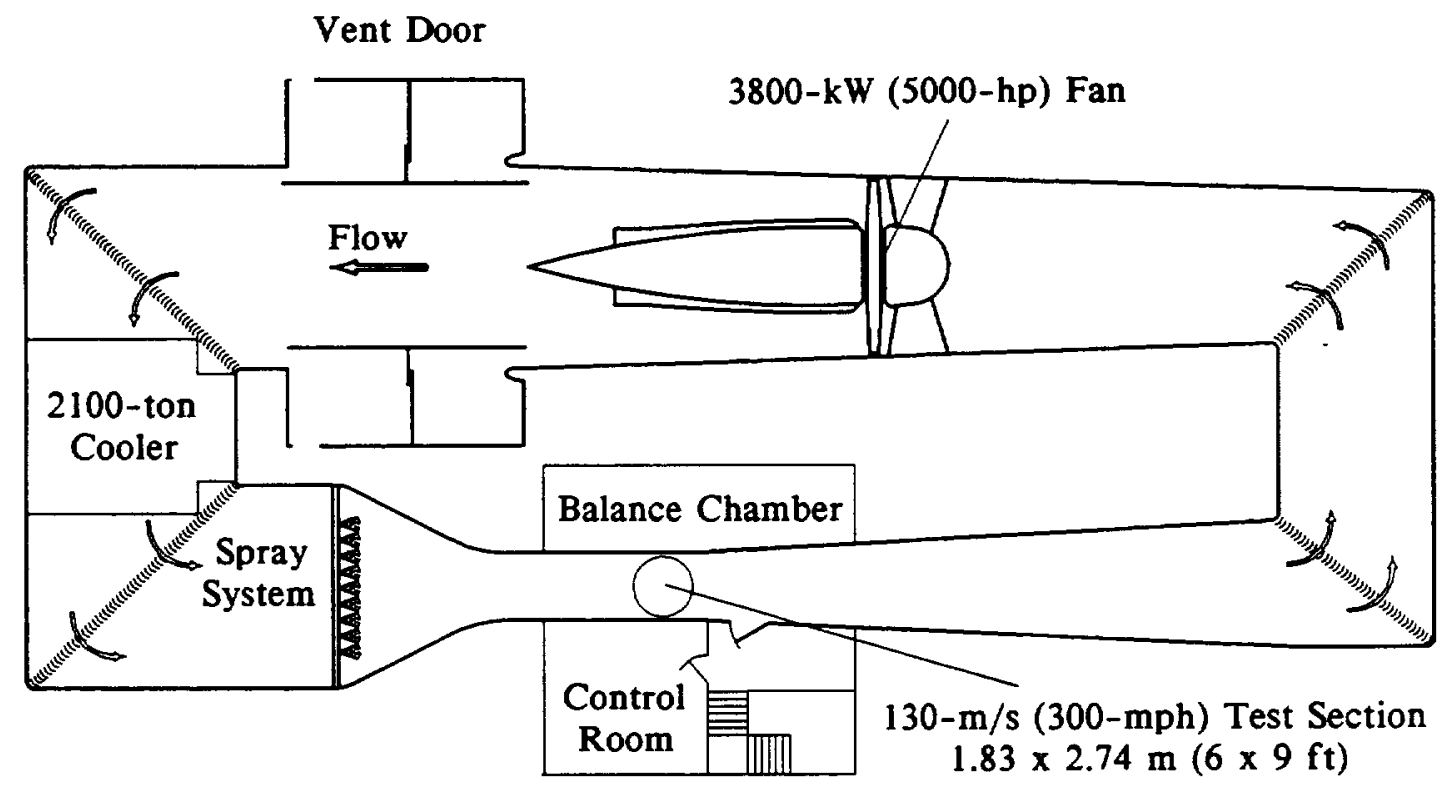

Figure 1. NASA Lewis Icing Research Tunnel.

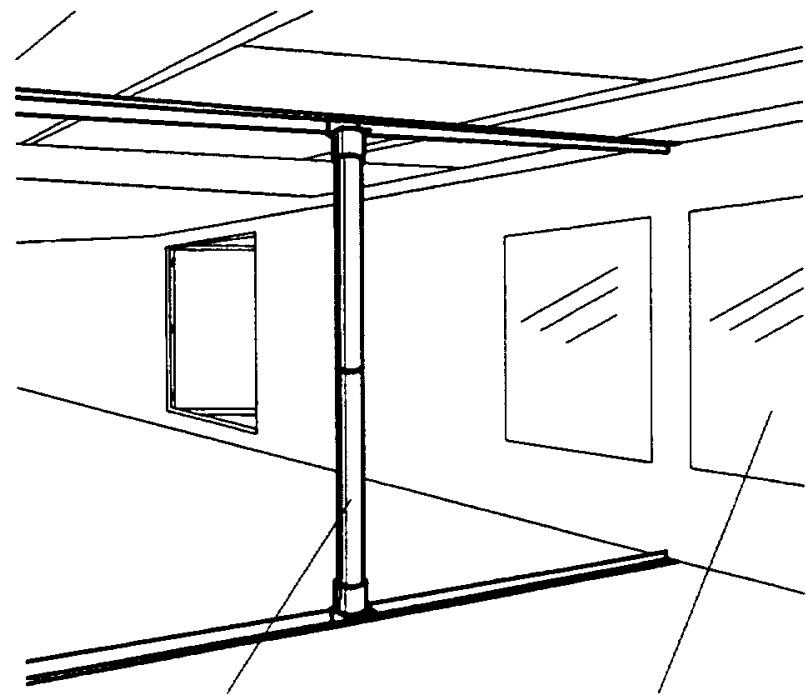

Test Cylinder
Control Room

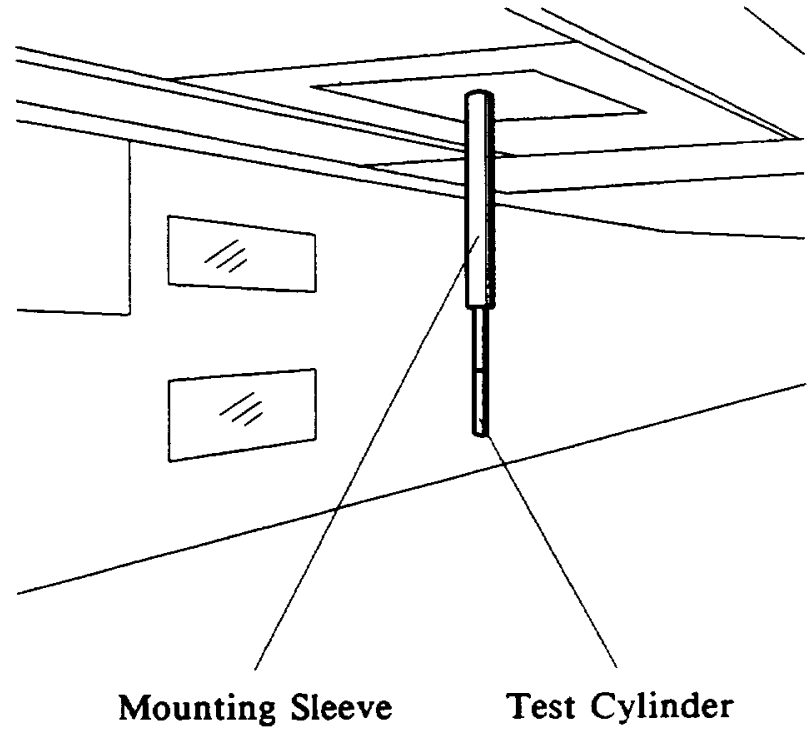

(b) $2.5-\mathrm{cm}(1-\mathrm{in})$ Cylinder.

(a) $5.1-$ to $15.2-\mathrm{cm}(2-$ to 6 -in) Cylinders.

Figure 2. Test Cylinder Installed in IRT Test Section. 


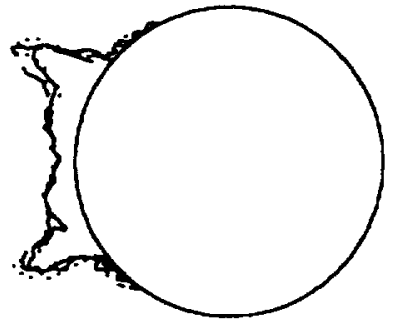

8-11-92 Run 6

- 1-6-93 Run 2

1-6-93 Run 12

(a) Cylinder Diameter, $15.2 \mathrm{~cm}$ (6 in).

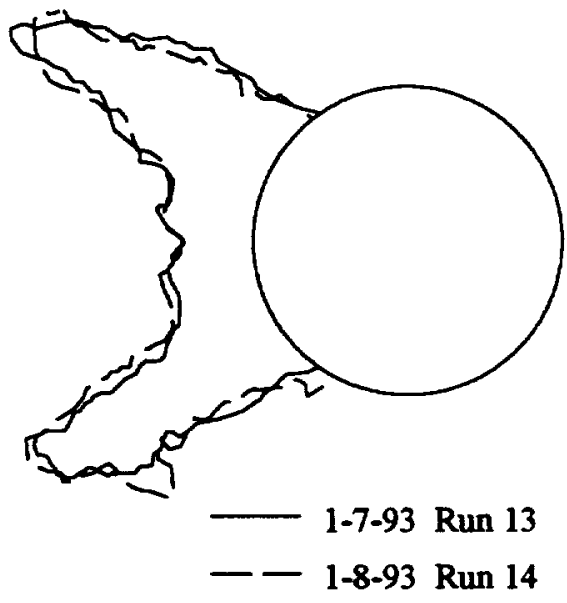

(b) Cylinder Diameter, $5.1 \mathrm{~cm}$ (2 in).

Figure 3. Typical Ice Shape Repeatability. Total Temperature, $-8^{\circ} \mathrm{C}\left(18^{\circ} \mathrm{F}\right)$; Velocity, $94 \mathrm{~m} / \mathrm{s}(210 \mathrm{mph}$; Droplet Median Volume Diameter, $30 \mu \mathrm{m}$; Liquid-Water Content, $1.3 \mathrm{~g} / \mathrm{m}^{3}$; Icing Spray Time, $7.8 \mathrm{~min}$.

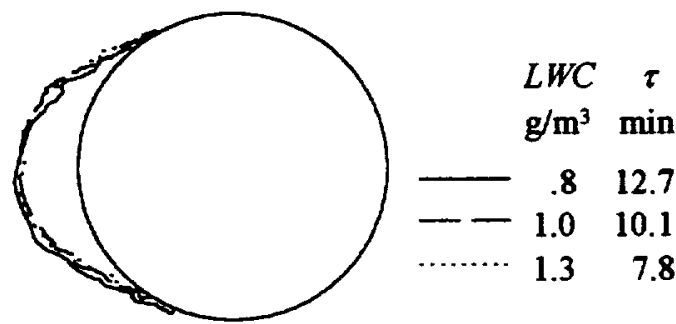

(a) Rime Ice; Cylinder Diam., $15.2 \mathrm{~cm}(6 \mathrm{in})$; Total Temp., $-26^{\circ} \mathrm{C}\left(-14^{\circ} \mathrm{F}\right)$; Droplet Median Volume Diam., $30 \mu \mathrm{m}$.

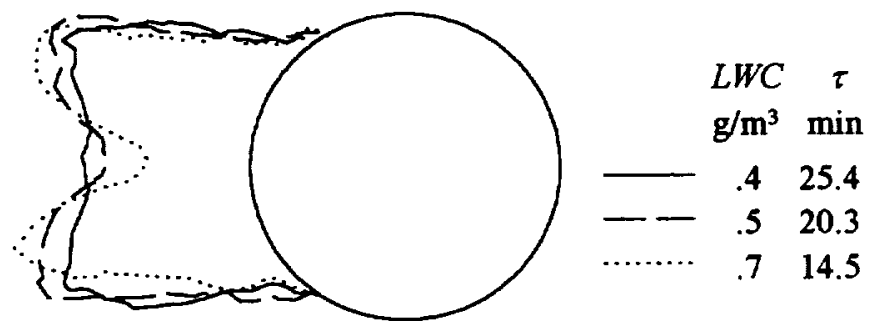

(b) Mixed Ice; Cylinder Diam., $5.1 \mathrm{~cm}$ ( 2 in); Total Temp., $-8^{\circ} \mathrm{C}\left(18^{\circ} \mathrm{F}\right)$; Droplet Median Volume Diam., $20 \mu \mathrm{m}$.

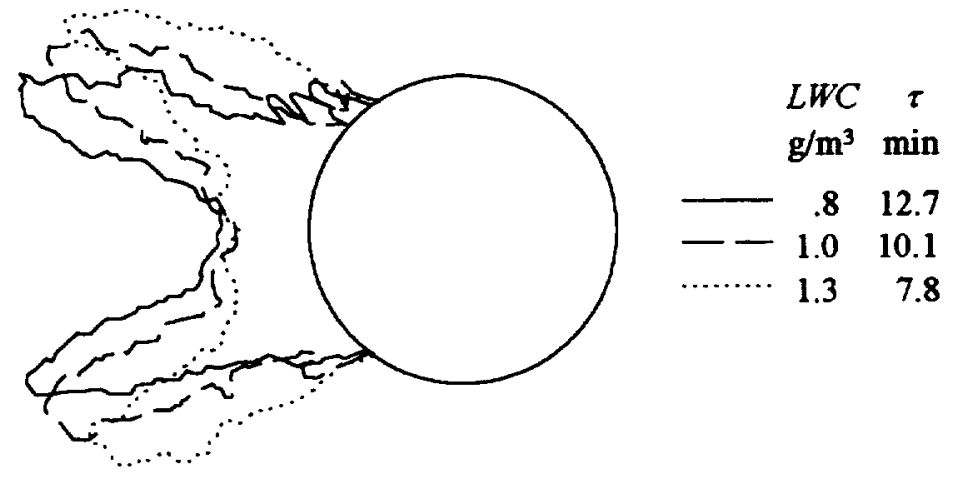

(c) Glaze Ice; Cylinder Diam., $5.1 \mathrm{~cm}$ (2 in); Total Temp., $-8^{\circ} \mathrm{C}\left(18^{\circ} \mathrm{F}\right)$; Droplet Median Volume Diameter, $30 \mu \mathrm{m}$.

Figure 4. Scaling With $L W C \times$ Time = Constant. Velocity, $94 \mathrm{~m} / \mathrm{s}(210 \mathrm{mph}) ; L W C \times \tau, 10.15 \mathrm{~g} \mathrm{~min} / \mathrm{m}^{3}$. 


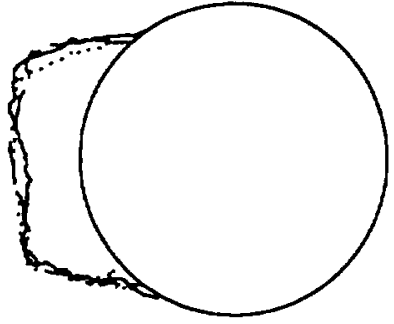

$\begin{array}{lllllll}c & t_{\text {tot }} & V & \delta & L W C & \tau\end{array}$

cm ${ }^{\circ} \mathrm{C} \mathrm{m} / \mathrm{s} \mu \mathrm{m} \mathrm{g} / \mathrm{m}^{3} \mathrm{~min}$

$\begin{array}{lllllll}\text { Reference } & 15.2 & -13 & 76 & 28 & .8 & 18.3\end{array}$

$\begin{array}{lllllll}\text { Swedish-Russian } & 7.6 & -14 & 61 & 22 & .8 & 11.4\end{array}$

$\begin{array}{lllllll}\text { French } & 7.6 & -14 & 61 & 20 & .95 & 9.5\end{array}$

(a) Reference Cylinder Diam., $15.2 \mathrm{~cm}$ (6 in).

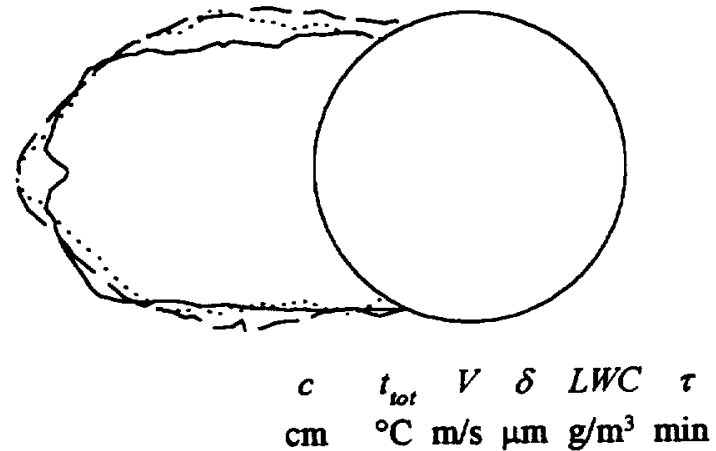

Reference

$\begin{array}{llllll}5.1 & -26 & 94 & 30 & 1.3 & 7.8\end{array}$

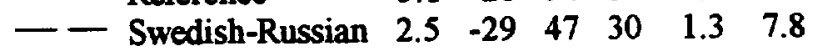

French

(b) Reference Cylinder Diam., $5.1 \mathrm{~cm}$ ( 2 in).

Figure 5. Scaling both Size and Velocity With Swedish-Russian and French Laws. Rime Conditions.

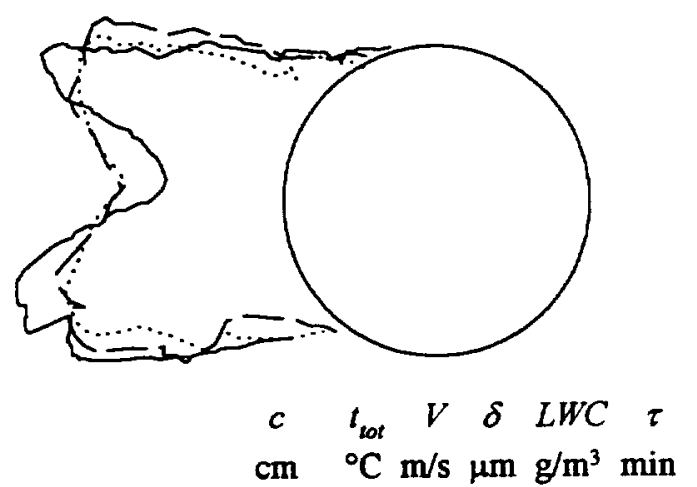

$\begin{array}{lrrrrrr}\text { Reference } & 5.1 & -8 & 94 & 30 & .6 & 16.9 \\ \text { Swedish-Russian } & 2.5 & -8 & 94 & 21 & .6 & 8.4\end{array}$

$\begin{array}{lllllll}\text { French } & 2.5 & -8 & 94 & 20 & .7 & 7.4\end{array}$

(a) Scaling Size With Velocity Matched.

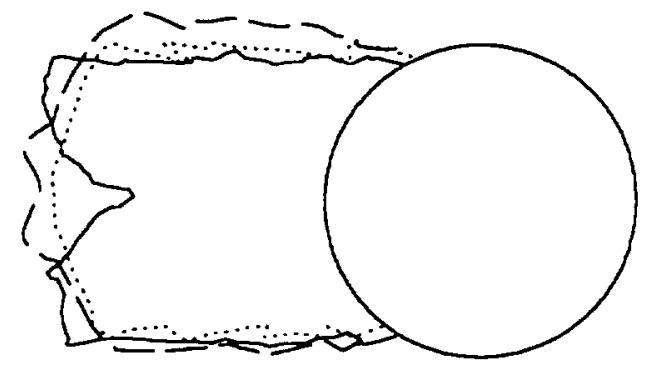

$\begin{array}{lllllll}c & t_{\text {tot }} & V & \delta & L W C & \tau\end{array}$

cm ${ }^{\circ} \mathrm{C} \mathrm{m} / \mathrm{s} \mu \mathrm{m} \mathrm{g} / \mathrm{m}^{3} \mathrm{~min}$

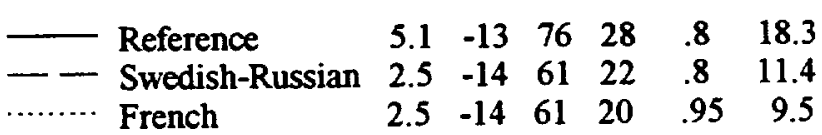

(b) Scaling Both Size and Velocity.

Figure 6. Scaling With Swedish-Russian and French Laws. Mixed-Ice Conditions; Reference Cylinder Diameter, $5.1 \mathrm{~cm}(2 \mathrm{in})$.

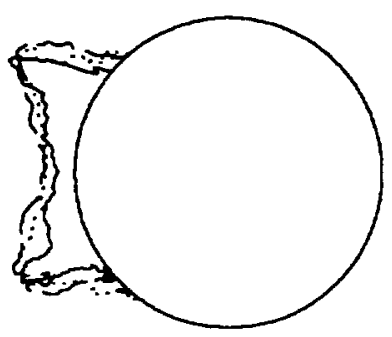

$\begin{array}{lllllllllllllll}c & t_{\text {tot }} & V & \delta & L W C & \tau\end{array}$ $\mathrm{cm} \quad{ }^{\circ} \mathrm{C} \mathrm{m} / \mathrm{s} \mu \mathrm{m} \mathrm{g} / \mathrm{m}^{3} \mathrm{~min}$

$\begin{array}{lllllll}\text { Reference } & 15.2 & -8 & 94 & 30 & 1.3 & 7.8\end{array}$

$\begin{array}{llllll}\text { Swedish-Russian } 15.2 & -11 & 58 & 38 & 1.3 & 12.6\end{array}$

French

$\begin{array}{llllll}15.2 & -10 & 58 & 36 & 1.4 & 11.5\end{array}$

(a) Scaling Velocity With Size Matched. Reference Cylinder Diameter, $15.2 \mathrm{~cm}$ (6 in).

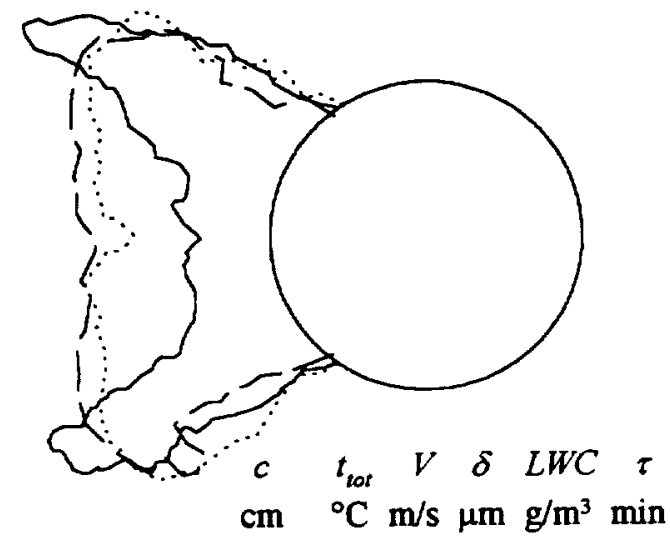

$\begin{array}{lllllll}\text { Reference } & 5.1 & -8 & 94 & 30 & 1.3 & 7.8\end{array}$

$\begin{array}{lllllll}\text { Swedish-Russian } & 2.5 & -11 & 58 & 27 & 1.3 & 6.3\end{array}$

French $\begin{array}{llllll}2.5 & -10 & 58 & 23 & 1.6 & 5.0\end{array}$

(b) Scaling Both Size and Velocity.

Reference Cylinder Diameter, $5.1 \mathrm{~cm}(2 \mathrm{in})$.

Figure 7. Scaling With Swedish-Russian and French Laws. Glaze-Ice Conditions. 
Public reporting burden for this collection of information is estimated to average 1 hour per response, including the time for reviewing instructions, searching existing data sources, gathering and maintaining the data needed, and completing and reviewing the collection of information. Send comments regarding this burden estimate or any other aspect of this collection of information, including suggestions for reducing this burden, to Washington Headquarters Services, Directorate for Intormation Operations and Reports. 1215 Jefferson Devis Highway, Suite 1204, Allington, VA 22202-4302, and to the Office of Management and Budget. Papenwork Reduction Project (0704-0188), Washington, DC 20503.

\begin{tabular}{|l|c|c|}
\hline 1. AGENCY USE ONLY (Leaveblank) & $\begin{array}{c}\text { 2. REPORT DATE } \\
\text { January } 1994\end{array}$ & $\begin{array}{r}\text { 3. REPORT TYPE ANDDATES COVERED } \\
\text { Technical Memorandum }\end{array}$
\end{tabular}

Rime-, Mixed- and Glaze-Ice Evaluations of Three Scaling Laws

\section{TITLE AND SUBTITLE}

5. FUNDING NUMBERS

WU-505-68-10

6. AUTHOR(S)

David N. Anderson

\section{PERFORMING ORGANIZATION NAME(S) AND ADDRESS(ES)}

National Aeronautics and Space Administration

Lewis Research Center

Cleveland, Ohio 44135-3191

9. SPONSORINGMONITORING AGENCYNAME(S) AND ADDRESS(ES)

National Aeronautics and Space Administration

Washington, D.C. 20546-0001

NASA TM-106461

AIAA-94-0718
8. PERForming ORgANIZATION REPORT NUMBER

E-8323

10. SPONSORING/MONITORING AGENCY REPORT NUMBER

\section{SUPPLEMENTARY NOTES}

Prepared for the AIAA 32nd Aerospace Sciences Meeting sponsored by the American Institute of Aeronautics and Astronautics, Reno, Nevada, January 10-13, 1994. Responsible person, David N. Anderson, (216) 433-3585.

\begin{tabular}{l|l|}
\hline 12a. DISTRIBUTIONAVAILABILITY STATEMENT \\
Unclassified - Unlimited \\
Subject Category 03
\end{tabular}

\section{ABSTRACT (Maximum 200 words)}

This report presents the results of tests at NASA Lewis to evaluate three icing scaling relationships or "laws" for an unheated model. The laws were $L W C \times$ time = constant, one proposed by a Swedish-Russian group and one used at ONERA in France. Icing tests were performed in the NASA Lewis Icing Research Tunnel (IRT) with cylinders ranging from 2.5 - to $15.2-\mathrm{cm}$ diameter. Reference conditions were chosen to provide rime, mixed and glaze ice. Scaled conditions were tested for several scenarios of size and velocity scaling, and the resulting ice shapes compared. For rime-ice conditions, all three of the scaling laws provided scaled ice shapes which closely matched reference ice shapes. For mixed ice and for glaze ice none of the scaling laws produced consistently good simulation of the reference ice shapes. Explanations for the observed results are proposed, and scaling issues requiring further study are identified.

\begin{tabular}{|c|c|}
\hline 14. SUBJECT TERMS \\
Icing; Scaling; Aircraft safety \\
\hline $\begin{array}{c}\text { 17. SECURITYCLASSIFICATION } \\
\text { OFREPORT } \\
\text { Unclassified }\end{array}$ & $\begin{array}{c}\text { 18. SECURITY CLASSIFICATION } \\
\text { OF THIS PAGE } \\
\text { Unclassified }\end{array}$ \\
\hline
\end{tabular}

\begin{tabular}{|c|c|}
\hline & $\begin{array}{c}\text { 15. NUMBER OFPAGES } \\
15\end{array}$ \\
\hline & $\begin{array}{r}\text { 16. PRICE CODE } \\
\mathrm{A} 03\end{array}$ \\
\hline $\begin{array}{l}\text { 19. SECUAITY CLASSIFICATION } \\
\text { OF ABSTRACT } \\
\text { Unclassified }\end{array}$ & 20. LIMITATION OF ABSTRACT \\
\hline
\end{tabular}

